\title{
Comparison of Soil and Corn Kernel Aspergillus flavus Populations: Evidence for Niche Specialization
}

\author{
Rebecca Ruth Sweany, Kenneth Eugene Damann, Jr., and Michael Douglas Kaller
}

First and second authors: Department of Plant Pathology and Crop Physiology, and third author: School of Renewable Natural Resources, Louisiana State University AgCenter, Baton Rouge 70803.

Accepted for publication 6 March 2011.

\section{ABSTRACT}

Sweany, R. R., Damann, K. E., Jr., and Kaller, M. D. 2011. Comparison of soil and corn kernel Aspergillus flavus populations: Evidence for niche specialization. Phytopathology 101:952-959.

Aspergillus flavus is considered a generalist-opportunistic pathogen, but studies are beginning to show that $A$. flavus populations have strains specific to various hosts. The research objective was to determine whether A. flavus soil populations consist of solely saprophytic strains and strains which can be facultatively parasitic on corn. A. flavus was isolated from both corn kernels and soil within 11 Louisiana fields. Sixteen vegetative compatibility groups (VCGs) were identified among 255 soil isolates. Only 6 of the 16 VCGs were identified in the 612 corn isolates and $88 \%$ of corn isolates were in two VCGs, whereas only $5 \%$ of soil isolates belonged to the same two VCGs. Isolates were characterized for aflatoxin $\mathrm{B}_{1}$ production and sclerotial size. A random subset of the isolates (99 from corn and 91 from soil) were further characterized for simplesequence repeat (SSR) haplotype and mating type. SSR polymorphisms revealed 26 haplotypes in the corn isolates and 78 in the soil isolates, and only 1 haplotype was shared between soil and corn isolates. Corn and soil populations were highly significantly different for all variables. Differences between corn and soil populations indicate that some soil isolates are not found in corn and some isolates have become specialized to infect corn. Further understanding of A. flavus virulence is important for development of resistant hybrids and for better biological control against toxigenic A. flavus.
Aspergillus flavus is an ascomycete fungus that infects and contaminates many economically important crops with aflatoxins. These include corn, cotton, peanut, and many tree nuts and, in Louisiana, it constantly threatens corn $(20,47,51)$. Many strains of A. flavus have the ability to produce mycotoxins called aflatoxins which can be acutely toxic and carcinogenic. A. flavus is ubiquitous and genetically and phenotypically very diverse $(20,47,51)$. The primary source of $A$. flavus inoculum is soil. The highest concentrations of A. flavus in soil are found in fields of highly susceptible crops, but $A$. flavus is also found on forest floors where there are not many known hosts, reflecting its saprophytic ability (20). In a cultivated field, the soil population of $A$. flavus increases after harvest and during hot, drought events (32) and has an aggregate or patchy spatial distribution within fields (20).

Populations of A. flavus isolates are characterized in many ways. One of the most common is to determine what types of toxins are produced. There are four types of aflatoxin: aflatoxin $\mathrm{B}_{1}\left(\mathrm{AFB}_{1}\right)$; aflatoxin $\mathrm{B}_{2}\left(\mathrm{AFB}_{2}\right)$, which may be produced by $A$. flavus; and aflatoxin $\mathrm{G}_{1}\left(\mathrm{AFG}_{1}\right)$, and aflatoxin $\mathrm{G}_{2}\left(\mathrm{AFG}_{2}\right)$, produced by related Aspergillus spp. but not A. flavus $(34,37,38,45)$. $\mathrm{AFB}_{1}$ is the most important aflatoxin due to its greater toxicity. Another method is sclerotial size. Sclerotia are considered small if the diameter is $<400 \mu \mathrm{m}$ and large if $>400 \mu \mathrm{m}(1,3,14,16$, $20,32,37,38,44,47)$. A. flavus strains have been characterized as belonging to cryptic species groups I or II based on five gene sequences $(14,15)$. Group I consists of isolates that produce both large and small sclerotia and, if toxigenic, only produce B aflatoxins, while group II isolates produce small sclerotia and, if toxi-

Corresponding author: R. R. Sweany; E-mail address: rswean1@tigers.lsu.edu

* The $\boldsymbol{e}$-Xtra logo stands for "electronic extra" and indicates that the online version contains one supplemental table.

doi:10.1094/PHYTO-09-10-0243

(c) 2011 The American Phytopathological Society genic, may produce both B and $\mathrm{G}$ aflatoxins (14). Unfortunately, atoxigenic isolates with small sclerotia cannot be assigned to either group I or II based on sclerotial size and toxin production alone, meaning classification based on sclerotial size and toxin production does not always give insight into the genetic relatedness of strains (14). More recently, taxonomists have excluded AFG-producing ability from A. flavus and renamed the Gproducing isolates from cryptic species II A. minisclerotigenes $(34,45)$. Several DNA-fingerprinting methods have been developed to characterize isolates using simple-sequence repeat (SSR) loci and restriction fragment length polymorphisms (RFLPs) $(17,18,26,30,50)$. Additionally, now that a sexual cycle has been identified (23), A. flavus isolates can be characterized into one of two mating types, Mat1-1 and Mat1-2 $(18,36)$. Another classification method is based on vegetative compatibility groups (VCGs) $(6,20,22,33)$. Isolates in the same VCG presumably have the same alleles for all compatibility loci and when paired hyphae fuse to form heterokaryons (33). Relatively few population studies use VCGs to characterize A. flavus isolates because determination of VCGs is labor intensive. Isolates in different VCGs differ in sclerotial size, mating type, aflatoxin production, and intraspecific aflatoxin inhibition $(6,18,20,22,25,31)$. However, isolates in the same VCG tend to produce the same kinds of mycotoxins and have the same sclerotial size and mating type $(6,18,22)$. It should not be surprising that strains in the same VCG would have similar characteristics because they represent a quasiclonal lineage. Grubisha and Cotty were unable to detect migration of genes among three VCGs based on 24 SSR loci (18). However, VCG is not a barrier to mating because Horn et al. were able to produce viable sexual offspring from 11 matings between isolates of different VCGs (23). More work is necessary to determine whether or not sexual reproduction occurs in nature.

A. flavus is generally thought to be an opportunistic pathogen, and it is believed that all strains are equally capable of infecting crops if the environmental conditions are conducive $(20,42$, 
47,51). There is conflicting evidence of specificity between different strains of $A$. flavus and infection of susceptible crops. It is commonly understood that A. flavus infects crops more readily than closely related $A$. parasiticus. However, it was not thought that there would be large differences among A. flavus strains in their abilities to infect crops $(20,22)$. In one study, corn kernels, bean leaves, and insects became infected by all isolates of $A$. flavus when the tissues were mechanically wounded (42). A. flavus does not require a wound to infect a crop; therefore, this study does not show whether there are any differences in the pathogenicity of strains under natural conditions $(20,29,42,47)$. It has been demonstrated that isolates from different crops in Argentina (44) and in Mississippi and Arkansas (1) produce different quantities of aflatoxin, indicating the possibility that there are different strains of A. flavus among the crops, and these different strains of A. flavus are better at infecting different crops. This may not actually be the case because isolates of A. flavus can quickly lose their ability to produce aflatoxin in serial transfers; therefore, aflatoxin production may not differentiate between strains of $A$. flavus (21). Evidence supporting specificity between peanut and different $A$. flavus VCGs in a single field showed that some VCGs only infrequently found in soil were more common in the peanut $(20,22)$. Determining specificity for cotton and corn is more complex than for peanut because peanut plants are infected by direct contact of the peg with the soil, whereas infection of cotton and corn requires either an insect vector or airborne dissemination of conidia from the soil to infect the seed $(6,20$, 29,47). Vectored and airborne infections allow the source of the inoculum to come from relatively distant areas $(20,29,47)$. In a single field in Arizona, comparisons of VCGs from the soil and cotton seed revealed that only two soil VCGs were found in the cotton seed and several VCGs were only isolated in the soil (6). Thus it appears that certain VCGs more specifically infect cotton $(6,20)$. Results supporting this finding come from a single field in Illinois where only two RFLP genotypes (correlated with VCG) were shared between 128 corn isolates and 31 soil isolates $(30,50)$. Unlike the studies on peanut and cotton, there were no predominant genotypes in the corn (50). There is not a clear case for specificity in corn; however, there were only two shared genotypes between the soil and corn, indicating that the soil and corn kernel populations are very different. In the present study, we have examined corn and soil A. flavus isolates and find, based on VCG analysis, aflatoxin production, sclerotial size, SSR haplotype, and mating type, that only certain soil isolates have become specialized to infect corn.

\section{MATERIALS AND METHODS}

Population sampling. In August 2007, soil and mature corn ears were sampled from 11 fields in seven parishes along the Red River and Mississippi River alluvial regions in Louisiana. Ten ears of corn and five soil samples were collected from each of seven fields from five parishes (Frogmore in Concordia Parish, Louisiana State University [LSU] AgCenter Macon Ridge Research Station and Crowville in Franklin Parish, Torbert in Point Coupee Parish, Beggs in St. Landry Parish, and LSU AgCenter Northeast Research Station and St. Joseph in Tensas Parish). The corn ears and soil samples were randomly selected from two diagonal transects originating from the middle of the outer edge of each field. Additionally, Francis Deville of Monsanto Company collected seven soil and seven corn ear samples from a field in Belcher, Caddo Parish; six corn ear and six soil samples in Chenyville, Rapides Parish; two corn ear and two soil samples in Batchelor, Point Coupee Parish; and four corn ear and four soil samples in Washington, St. Landry Parish. The corn ears were shelled and stored in paper bags at ambient temperature in the lab while the soil samples, in opened quart zip-lock bags, were allowed to dry in an exhaust hood.
Corn kernels from each shelled ear $(50 \mathrm{ml})$ were surface sterilized in a $6 \%$ bleach solution, and 25 intact corn kernels were plated on A. flavus/parasiticus (AFPA) medium amended with hygromycin at $50 \mu \mathrm{g} / \mathrm{ml}$, chlortetracycline at $1.5 \mu \mathrm{g} / \mathrm{ml}$, streptomycin at $30 \mu \mathrm{g} / \mathrm{ml}$, and Avermectin at $0.04 \mu \mathrm{l} / \mathrm{ml}(7,10,35)$. The 2,225 kernels on AFPA medium were incubated at $30^{\circ} \mathrm{C}$ for 5 days. AFPA is a selective and differential medium which suppresses conidiation and, when A. flavus or A. parasiticus grow, both species produce aspergillic acid that changes the color of the medium to a bright orange color $(7,10,35)$. A plug of mycelia was aseptically removed from the orange medium below each infected kernel. The plug was then transferred to V8 medium (5\% V8 juice and $2 \%$ agar, $\mathrm{pH}$ 5.2) containing Avermectin at $0.04 \mu \mathrm{l} / \mathrm{ml}$.

Each soil sample $(50 \mathrm{~g})$ was suspended in $100 \mathrm{ml}$ of autoclaved distilled water. A 1-ml aliquot of undiluted and two 1-ml aliquots of a 1-in-10 dilution of the soil suspension were spread on three petri dishes of amended AFPA medium. The soil dilution plates were incubated at $30^{\circ} \mathrm{C}$ for 5 days. For each 50 -g soil sample, orange colonies were transferred onto a V8 medium plate amended with Avermectin at $0.04 \mu \mathrm{g} / \mathrm{ml}$ amended.

At least five orange colonies were isolated from each soil and corn ear sample to provide sufficient degrees of freedom to meet the desired level of statistical precision. Single-conidium colonies were generated by streaking conidia from V8 medium onto potato dextrose agar (PDA) and growing overnight at $30^{\circ} \mathrm{C}$. A single germinating conidium was transferred onto V8 medium. The isolates were identified as A. flavus by the presence of smooth, olive-green conidia $(28,38)$. A conidial suspension from the V8 medium was made for each $A$. flavus isolate in glycerol/water $(1: 1, \mathrm{vol} / \mathrm{vol})$ and stored in the refrigerator or freezer.

VCGs. Nitrate nonutilizing (nit) mutants were generated to determine the VCG of the isolates $(5,33)$. The nit mutants were characterized by the type of nitrogen source utilized and classified as either $\operatorname{cn} x$ (hypoxanthine and nit), nirA (nitrite and nit), or niaD (nit) mutants $(5,33)$. All complementary nit mutants were plated on a starch modified Czapek-Dox medium plate 1 in. apart and incubated in ambient light at $30^{\circ} \mathrm{C}$ for 3 weeks $(5,11,33)$. Plates were observed for zones of dense conidiation which indicated a successful formation of a heterokaryon between two complementary mutants in the same VCG $(5,33)$.

Phenotypic traits: aflatoxin and sclerotial size. Each A. flavus isolate's conidial suspension $(20 \mu \mathrm{l})$ was inoculated on autoclaved rice $\left(5 \mathrm{ml}\right.$ of rice and $5 \mathrm{ml}$ of $\mathrm{H}_{2} \mathrm{O}$ in a $20-\mathrm{ml}$ scintillation vial) for

TABLE 1. Eight simple-sequence repeat (SSR) loci forward and reverse primers (26)

\begin{tabular}{lcl}
\hline Primer & \multicolumn{2}{c}{ Annealing } \\
temperature $\left({ }^{\circ} \mathrm{C}\right)$ & \multicolumn{1}{c}{ Sequence 5'-3' } \\
\hline 347-ACT70-F & 51 & CAAGGTTGGCTAATCGGCA \\
347-ACT70-R & 51 & TAACAGGCGGTAGCAGAGCA \\
327-TAA41-F & 51 & TGCCTAAAGCTCCTTCCTCC \\
327-TAA41-R & 51 & CGGCTGTGTCGGCTATTA \\
277-TTC32-F & 50 & CAACCCAGGAGTTCTGATGC \\
277-TTC32-R & 50 & TGCTATCTGCCTTGGAGACG \\
250-TTC23-F & 50 & GTGGTTCCTGTTTGCATGG \\
250-TTC23-R & 50 & CTTTCTTGCCTTAGGCAGTCT \\
205-TTTC17-F & 52 & CTCTTCTTCGCCGGTCTTGT \\
205-TTTC17-R & 52 & GCAGTGAGGCCCTTTCTTG \\
146-TTC18-F & 51 & GCGACCAGGATAAGCTCAAAG \\
146-TTC18-R & 51 & ACACGGTGCGAGAGACTTCA \\
177-TAA18-F & 53 & AGGAGAGGGAACCCAAGTCA \\
177-TAA18-R & 53 & CATTAAACGGTGCAGGATGGC \\
123-AC27-F & 52 & ACCCACCTTACCCACACCAAC \\
123-AC27-R & 52 & CAACCCTGCCAATCTTCCTC \\
\hline
\end{tabular}

${ }^{\mathrm{z}}$ First three digits indicate length of the amplified fragment based on the genome sequence of the Aspergillus flavus isolate (for example, NRRL $3357=$ 347), central letters and numbers indicate composition of SSR locus (for example, ACT70 indicates a locus consisting of 70 ACT repeats), F means forward, and $\mathrm{R}$ means reverse. 
$\mathrm{AFB}_{1}$ production (39). The conidial suspension concentrations were not standardized because Wicklow et al. (48) found that aflatoxin production was more a function of the amount of substrate rather than inoculum size. After 5 days at $30^{\circ} \mathrm{C}$ in ambient light, the vial was filled with chloroform and soaked overnight to extract the aflatoxin from the rice and fungus (39). The chloroform extract was then filtered through a Whatman number 1 $100-\mathrm{mm}$ filter paper funnel into a 100-ml glass beaker. The chloroform was allowed to evaporate under an exhaust hood and the aflatoxin was resuspended in $0.5 \mathrm{ml}$ of a methanol/water $(80: 20, \mathrm{vol} / \mathrm{vol})$ mixture (39). The extract was diluted with $0.5 \mathrm{ml}$ of acetonitrile and filtered through a cleanup column packed with $200 \mathrm{mg}$ of basic aluminum oxide into an autosampler vial (40).

The aflatoxin was quantified with reversed-phase high-performance liquid chromatography (HPLC) using a Summit HPLC System (Dionex Corporation, California) with a P580 pump, ASI100 automated sample injector, RF2000 fluorescence detector, and Chromeleon software version 6.20 (27). A post-column derivatization step was conducted by exposure to UV light in a Photochemical Reactor for Enhanced Detection (Aura Industries Inc., New York) (27). The mobile phase was HPLC grade methanol/HPLC grade acetonitrile/distilled water (22.5:22.5:55, $\mathrm{vol} / \mathrm{vol}$ ) at $1 \mathrm{ml} / \mathrm{min}$. The stationary phase was an Acclaim 120 C18, 3- $\mu \mathrm{m}, 120-\AA$, 4.6-by-150-mm column (Dionex Corporation). $\mathrm{AFB}_{1}$ was detected at $9.2 \mathrm{~min}$. The $\mathrm{G}$ toxins were not detected because the rice substrate created background peaks in the chromatograms, which eluted at the same time as $G$ toxins would if they were present.

All of the isolates were grown on 4-ml PDA slants in 15-by$100-\mathrm{mm}$ test tubes in an ambient light incubator at $30^{\circ} \mathrm{C}$ for 1 month. Diameters of at least 10 sclerotia were determined to be large or small on a compound light microscope with the aid of an ocular micrometer. Sclerotia $>400 \mu \mathrm{m}$ were classified as large and sclerotia $<400 \mu \mathrm{m}$ were classified as small $(1,3,14,16,20,32$, $37,38,44,47)$. Also, some isolates produced sclerotia of both sizes. If only a few sclerotia were of a different size, the isolate was considered the majority class; however, if sclerotia of both size classes were observed with the same frequency, the isolates were put into a fourth class of both large and small sclerotia.

Genotypic traits: SSR haplotypes and mating type loci. SSR fingerprints and mating types were obtained from a subsample of nine random number-selected corn isolates and nine random number-selected soil isolates from each of 11 fields, except only two isolates from the soil samples from Beggs, St. Landry Parish and eight isolates from the soil samples from Frogmore, Concordia Parish were selected. In total, 99 of 612 corn isolates and 91 of 255 soil isolates were fingerprinted and haplotypes determined.

Each of the 190 isolates was grown on PDA in a standard 100-by-15-mm petri dish. All the conidia were then scraped into $600 \mu \mathrm{l}$ of Nuclei Lysis solution (Promega Corp., Madison, WI) in a 1.5-ml microcentrifuge tube, ground with a micropestle, and DNA was extracted following the Promega protocol (2). The concentration of DNA was measured with a ND-1000 spectrophotometer (Nanodrop, Delaware) and then all the extracts were diluted to $10 \mu \mathrm{g} / \mathrm{ml}$ with Tris-EDTA buffer, $\mathrm{pH} 8$.

Eight SSR loci were selected by C. Huang $(25,26)$ using sequence data of A. flavus isolate NRRL 3357, provided by W. Nierman of the J. Craig Venter Institute in Rockville, MD. These consisted of three (TTC)n repeats, one (AC)n repeat, one (ACT)n repeat, two (TTA)n repeats, and one (TTTC)n repeat. Forward and reverse primers flanking these loci were used to amplify the SSRs (Table 1). Amplifications were done in a Cetus DNA Thermal cycler (Perkin-Elmer Inc., Massachusetts) using PuReTaq Ready-To-Go polymerase chain reaction (PCR) beads (GE Healthcare, Buckinghamshire, UK). The PCR reactions were done according to the manufacturer's guidelines with a final con- centration of $0.24 \mu \mathrm{M}$ for both the forward and reverse primers for a particular SSR locus and $10 \mathrm{ng}$ of DNA. The PCR program consisted of: an initial 210 -s denaturation step at $95^{\circ} \mathrm{C} ; 35$ cycles of $15 \mathrm{~s}$ of denaturation at $95^{\circ} \mathrm{C}$, a 20 -s annealing step at the temperature specified in Table 1 , and a 30 -s extension step at $72^{\circ} \mathrm{C}$; and final extension at $72^{\circ} \mathrm{C}$ for $120 \mathrm{~s}$. The samples were held at $4{ }^{\circ} \mathrm{C}$.

The mating types were determined in a multiplex PCR reaction (36). A concentration of $0.5 \mu \mathrm{M}$ of both the Mat1-1 and Mat1-2 forward and reverse primers and $10 \mathrm{ng}$ of DNA were added to 0.5-ml tubes of PuReTaq Ready-To-Go PCR beads (GE Healthcare) and mixed to the manufacturer's guidelines (36). The PCR amplifications were conducted in a Cetus DNA Thermal cycler (Perkin-Elmer Inc.) with an initial 5-min denaturation step at $95^{\circ} \mathrm{C}$ and 40 cycles of $30 \mathrm{~s}$ at $95^{\circ} \mathrm{C}, 60 \mathrm{~s}$ at $54^{\circ} \mathrm{C}$, and $45 \mathrm{~s}$ at $72^{\circ} \mathrm{C}$.

The amplified DNA from the PCR reactions and an Ultraclean 20-bp ladder (MoBio Laboratories Inc., California) were separated with a subcell agarose gel electrophoresis system (model 192; Bio-Rad Laboratories, Hercules, CA) with a $3 \%$ GenePure Sieve GQA Agarose gel (ISC BioExpress, Utah) made with $0.5 \times$ Tris-borate-EDTA. The DNA was stained with 3-EZ-vision DNA dye as loading buffer (Amresco Inc., Ohio), which fluoresced when exposed to UV light, and a digital image was captured in the Gel Logic 1500 imaging system (Carestream Health Inc., New York). Photos of the gels were edited with Kodak Molecular Imaging Software (version 4.5; Kodak, New York). The sizes of the SSR and mating type bands were determined using BioNumerics (version 3.0; Applied Maths BVBA, Ghent, Belgium). The Mat1-1 mating type diagnostic amplicon is $395 \mathrm{bp}$ and Mat 1-2 is $273 \mathrm{bp}$ (36). The SSR bands were assigned to different size classes using BioNumerics software and were placed in different groups using the tolerance settings of $0.50 \%$ optimization and $1.00 \%$ position tolerance. Additionally, the band assignments were double checked by eye and new band classes were assigned as needed. The eight SSR classes for each isolate were combined and considered a haplotype or fingerprint.

Analysis. Descriptive statistics and hypothesis testing were evaluated using SAS for Windows (version 9.2; SAS Institute, Cary, NC). Multicategory logit generalized linear models were created to compare soil and corn kernel populations with VCGs, mating type loci, sclerotia groups, and $\mathrm{AFB}_{1}$ groups (13). In these models, the fields were pooled for each linear model. In all models, soil and corn source served as the explanatory variable and the VCG, mating type loci, sclerotia, and $\mathrm{AFB}_{1}$ group membership were the response variables. Only the nine most abundant VCGs were used in the VCG linear model. Inclusion of additional VCGs resulted in unacceptably high overdispersion, as measured by $\chi^{2}$ or degrees of freedom; therefore, only those nine VCGs were analyzed. Although sclerotia were measured, all isolates were classified as either having none, small $(<400 \mu \mathrm{m})$, or large sclerotia $(>400 \mu \mathrm{m})(1,3,14,16,20,32,37,38,44)$. Continuous $\mathrm{AFB}_{1}$ data were converted to categories (zero, low, medium, and high) because of nonhomogenous variances between soil and corn sample groups. The models were interpreted with an $\alpha$ of 0.05 , and goodness-of-fit (i.e., whether one type of explanatory variable was a better description of the data compared with competing alternatives) was assessed with the Akaike information criterion (AIC), with lower AIC values suggesting better fit and more explanatory ability. Each unique combination of SSR alleles found among the isolates was assigned a new haplotype. Unbiased haplotype diversities were calculated for both the soil and corn kernel isolates in each field based on the proportion of different haplotypes in a field $(19,46)$. A value of one meant the field was completely diverse (no two isolates alike) and zero meant there was no diversity in the field (all isolates identical). The formula for unbiased haplotype diversity was $H_{e}=[n /(n-1)] \times\left(1-\Sigma p_{i}^{2}\right)$, where $i$ was the $i$ th haplotype and $n$ was the number of corn 
kernels or soil isolates within a field (46). Analysis of molecular variance was performed using the differences in SSR bands for all isolates to determine whether the soil and corn kernel populations were different using Arlequin (version 3.11; Computational and Molecular Population Genetics Lab, University of Berne, Switzerland) $(19,40,46)$.

\section{RESULTS}

Population sampling. In total, 867 A. flavus colonies were isolated: 612 isolates from corn kernels from 89 corn ears and 255 isolates from 54 soil samples. The frequency of A. flavus isolation varied between fields and between soil and corn samples. The mean number of A. flavus colonies isolated from a field was $23 \pm$ 4 (standard error [SE]) colonies in the soil and $56 \pm 12$ (SE) in the corn kernels. The mean number of colonies in a soil sample was $6 \pm 1(\mathrm{SE})$ and $7 \pm 1(\mathrm{SE})$ in a corn ear sample.

VCGs. In all, 16 different VCGs were identified out of 594 corn nit mutants and 235 soil nit mutants. A total of 18 corn isolates and 20 soil isolates failed to produce nit mutants after successive tries. In total, 32 of 594 corn nit mutants and 129 of 235 soil nit mutants did not form heterokaryons with any nit mutants in the $16 \mathrm{VCGs}$ and, thus, were distinct from isolates within the 16 VCGs. It is unknown whether these isolates are in singleton VCGs or in multiple different VCGs because they were not tested against each other due to the fact that only one nit mutant was produced per isolate. Multiple VCGs were found in both single soil and single corn ear samples. VCGs 1 and 4 were the only VCGs to be found in all 11 fields and accounted for $88 \%$ of corn kernel isolates (Table 2). Eight VCGs consisted of isolates with consistent sclerotial size. From VCG 10 and 13, 5 of 12 and 2 of 3 isolates, respectively, produced an equal proportion of small and large sclerotia. Isolates in $10 \mathrm{VCGs}$ all produced $\mathrm{AFB}_{1}$ in the same $\mathrm{AFB}_{1}$ quantity category.

Soil isolates were represented in all VCGs whereas corn isolates were only found in six VCGs (Table 2). The proportion of soil isolates and corn isolates in the same VCG varied for each VCG (Fig. 1). The probability of recovering isolates in VCGs 1, $2,3,4,5,7,8,9$, and 10 varied significantly between the corn and soil populations $\left(\chi^{2}=553.41, \mathrm{df}=8, P\right.$ value $<0.0001$, AIC $=$ 1,895).
Phenotypic traits: aflatoxin and sclerotial size. All A. flavus isolates produced a mean value of $\mathrm{AFB}_{1}$ at 4,658 \pm 9,526 (SE) $\mathrm{ppb}$. The mean aflatoxin $\mathrm{AFB}_{1}$ for corn kernel isolates was 2,314 $\pm 7,455$ (SE) $\mathrm{ppb}$ and 10,248 $\pm 11,430$ (SE) ppb for the soil isolates. There was a higher proportion of soil isolates with high levels of $\mathrm{AFB}_{1}$ and there was a higher proportion of the corn isolates with medium, low, and no toxin (Fig. 2). The probability of isolates in the different aflatoxin production groups differed significantly between the corn kernel and soil population $\left(\chi^{2}=\right.$ 334.79 , df $=3, P$ value $<0.0001$, AIC $=2,376$ ).

All isolates were classified as either having none, small $(<400 \mu \mathrm{m})$, or large sclerotia $(>400 \mu \mathrm{m})(1,3,14,16,20,32,37$, $38,44)$. The majority $(95 \%)$ of corn kernel isolates produced no sclerotia, whereas the majority $(97 \%)$ of soil isolates produced sclerotia (56\% small and $41 \%$ large sclerotia). The probability of isolates producing the same sclerotial size varied significantly between the corn kernel and soil populations $\left(\chi^{2}=1,094.02, \mathrm{df}=2\right.$, $P<0.0001$, AIC $=1,454$ ).

Genotypic traits: SSR haplotypes and mating type loci. In all, 103 different haplotypes were found within the 190 isolate subsample of the corn kernel and soil isolate population. In total, 26 haplotypes were found in the corn kernels, 78 haplotypes were in the soil samples, and only 1 haplotype in VCG1 was shared between soil and corn kernel isolates (Supplemental Table 1). Multiple haplotypes were found in the fields in both the soil and corn kernel samples and only 10 haplotypes were found in more than one field (Table 3). Within a field, the haplotypic diversities were higher for the soil samples than the corn samples. The mean differences in SSR loci varied significantly between the soil and corn kernel populations (Rst $=0.6033, \mathrm{df}=1, P$ value $<0.0001$ ) Multiple isolates for 13 of the 16 VCGs were characterized by SSR fingerprints; of those, only VCG 10 had a single haplotype (Table 2). Two VCGs had one SSR haplotype that was shared with an isolate that was determined to not be in the same VCG by nit complementation (Table 2).

Of the 99-isolate corn-kernel subsample, 96\% was Mat1-2 mating type whereas the 91-isolate soil subsample was more evenly distributed between the two mating types (48\% Mat1-1 and 52\% Mat1-2). The probability of corn and soil isolates in the two mating types differed significantly $\left(\chi^{2}=110.44\right.$, df $=1, P<$ $0.0001)$. Each VCG is only represented by one mating type, with

TABLE 2. Characteristics of Aspergillus flavus isolates in 16 vegetative compatibility groups (VCGs)

\begin{tabular}{|c|c|c|c|c|c|c|c|c|c|c|c|c|c|c|}
\hline \multirow[b]{2}{*}{ VCG } & \multirow[b]{2}{*}{ Count } & \multicolumn{3}{|c|}{ Number of isolates in } & \multicolumn{3}{|c|}{ Sclerotia $(\%)^{\mathrm{u}}$} & \multicolumn{4}{|c|}{$\operatorname{Toxin}(\%)^{\mathrm{v}}$} & \multicolumn{3}{|c|}{ Number of SSR haplotypesw } \\
\hline & & Soil & Corn & Fields & Zero & Small & Large & Zero & Low & Medium & High & Finger & Unique & Shared \\
\hline 1 & 487 & 4 & 483 & 11 & 99.8 & 0.2 & 0 & 5.4 & 89.5 & 5.2 & 0.0 & 70 & 6 & $13 \mathrm{~A}, 7 \mathrm{~B}, 31 \mathrm{C}^{\mathrm{x}}, 7 \mathrm{D}, 6 \mathrm{E}$ \\
\hline 2 & 29 & 29 & 0 & 2 & 0.0 & 0.0 & 100.0 & 0.0 & 0.0 & 0.0 & 100.0 & 7 & 4 & $3 \mathrm{~F}$ \\
\hline 3 & 6 & 6 & 0 & 4 & 0.0 & 100.0 & 0.0 & 0.0 & 0.0 & 0.0 & 100.0 & 3 & 3 & 0 \\
\hline 4 & 61 & 5 & 56 & 11 & 98.4 & 1.6 & 0.0 & 0.0 & 0.0 & 3.3 & 96.7 & 14 & 6 & $4 \mathrm{G}, 4 \mathrm{H}$ \\
\hline 5 & 11 & 10 & 1 & 3 & 0.0 & 100.0 & 0.0 & 0.0 & 0.0 & 0.0 & 100.0 & 5 & 3 & $2 \mathrm{I}^{\mathrm{y}}$ \\
\hline 6 & 5 & 5 & 0 & 2 & 0.0 & 100.0 & 0.0 & 20.0 & 80.0 & 0.0 & 0.0 & 2 & 2 & 0 \\
\hline 7 & 12 & 2 & 10 & 2 & 0.0 & 75.0 & 25.0 & 0.0 & 100.0 & 0.0 & 0.0 & 3 & 3 & 0 \\
\hline 8 & 14 & 14 & 0 & 4 & 0.0 & 92.9 & 7.1 & 0.0 & 14.3 & 7.1 & 78.6 & 6 & 4 & $2 \mathrm{~J}$ \\
\hline 9 & 16 & 14 & 2 & 4 & 12.5 & 12.5 & 75.0 & 0.0 & 0.0 & 0.0 & 100.0 & 8 & 4 & $4 \mathrm{~K}^{\mathrm{x}}$ \\
\hline 10 & 12 & 2 & 10 & 2 & $50.0^{z}$ & $41.7^{z}$ & $41.7^{z}$ & 83.3 & 16.7 & 0.0 & 0.0 & 5 & 0 & $5 \mathrm{~L}$ \\
\hline 11 & 2 & 2 & 0 & 2 & 0.0 & 0.0 & 100.0 & 0.0 & 0.0 & 0.0 & 100.0 & 1 & 1 & 0 \\
\hline 12 & 4 & 4 & 0 & 3 & 0.0 & 100.0 & 0.0 & 0.0 & 25.0 & 0.0 & 75.0 & 2 & 2 & 0 \\
\hline 13 & 3 & 3 & 0 & 1 & 0.0 & $66.7^{z}$ & $100.0^{\mathrm{z}}$ & 0.0 & 100.0 & 0.0 & 0.0 & 0 & $\ldots$ & $\ldots$ \\
\hline 14 & 2 & 2 & 0 & 1 & 0.0 & 50.0 & 50.0 & 0.0 & 100.0 & 0.0 & 0.0 & 1 & 1 & 0 \\
\hline 15 & 3 & 3 & 0 & 2 & 0.0 & 100.0 & 0.0 & 0.0 & 0.0 & 0.0 & 100.0 & 2 & 2 & 0 \\
\hline 16 & 2 & 2 & 0 & 1 & 0.0 & 0.0 & 100.0 & 0.0 & 0.0 & 0.0 & 100.0 & 2 & 1 & $1 \mathrm{M}^{\mathrm{y}}$ \\
\hline
\end{tabular}

u Small sclerotia diameters are $<400 \mu \mathrm{m}$ and large sclerotia diameters are $>400 \mu \mathrm{m}$.

${ }^{\mathrm{v}}$ Low aflatoxin $\mathrm{B}_{1}\left(\mathrm{AFB}_{1}\right)=\mathrm{AFB}_{1}>0$ and $\leq 20 \mathrm{ppb}$, medium $=\mathrm{AFB}_{1}>20$ and $\leq 300 \mathrm{ppb}$, and high $=\mathrm{AFB} \mathrm{B}_{1}>300 \mathrm{ppb}$.

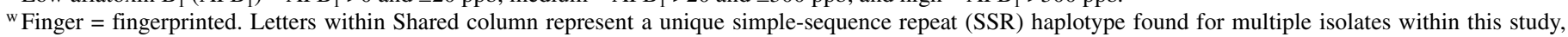
numbers are the number of isolates with the SSR haplotype found within the VCG.

x SSR haplotype was shared with two additional isolates that were not characterized by VCG due to lack of a nitrate nonutilizing (nit) mutant.

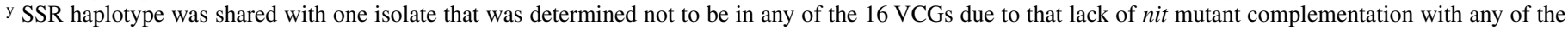
VCGs.

$\mathrm{z}$ Total percentage of isolates in VCG producing sclerotia is $>100$ because some isolates produced both large and small sclerotia. 
the exception of VCG1, with only 1 of the 71 isolates in the Mat1-1 mating type (Fig. 3).

\section{DISCUSSION}

The objective of this research was to determine whether certain strains of A. flavus in the soil were more specialized to infect corn than others. Such a result would imply that there were two ecotypes of A. flavus: one primarily saprophytic and the other facultatively parasitic. Because soil is the source of inoculum for infection of corn, it should have contained isolates of both ecotypes. The results showed that different VCGs predominated on the corn and in the soil, providing evidence for two A. flavus ecotypes with different abilities to occupy these two niches. Isolates within VCGs varied in their production of aflatoxin and sclerotia. The soil and corn A. flavus populations differed in the sclerotial sizes, $\mathrm{AFB}_{1}$ production, mating types, and eight SSR locus haplotypes. Even though these variables differentiated the soil and corn kernel A. flavus populations, these metrics were not as good as VCGs for comparing strains of A. flavus.

Our results were similar to recent findings on cotton and peanut. These indicate that VCGs varied between soil $A$. flavus isolates and cotton and peanut $A$. flavus isolates and demonstrated that isolates of different VCGs have different specific abilities to infect peanut and cotton (6,22). Like peanut and cotton, the VCG assemblages varied significantly between soil and corn populations in this study. The soil contained all of the six identified VCGs from the corn (15\% soil isolates and $93 \%$ corn isolates) as
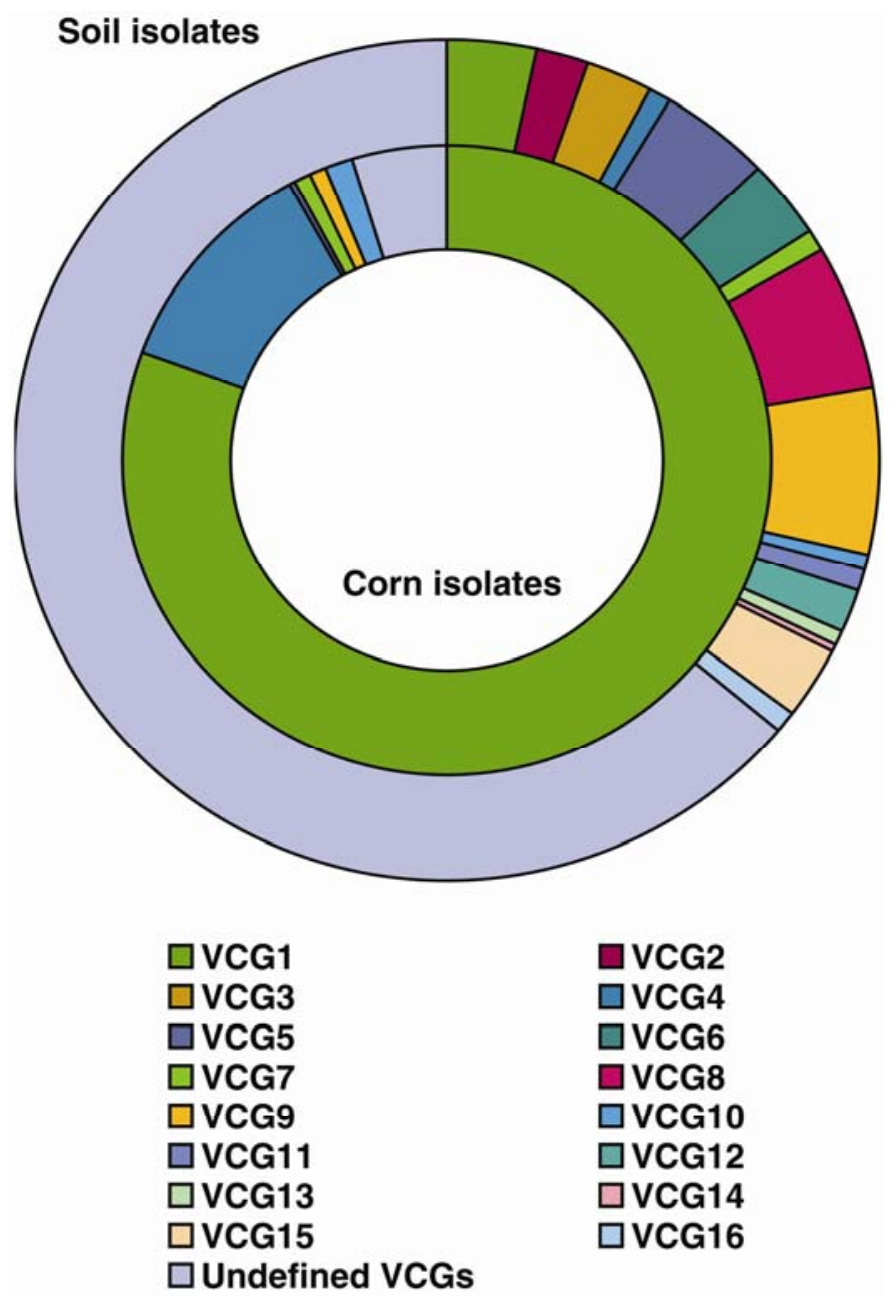

Fig. 1. Different vegetative compatibility group (VCG) assemblages between soil and corn kernel Aspergillus flavus populations. Circle slices are the mean proportion of corn or soil A. flavus isolates in all samples. well as additional identified (27\% soil isolates) and unidentified VCGs (51\% soil isolates); this suggests a greater diversity of VCGs in the soil than in the corn (Table 2; Fig. 1). Consequently, it appears that only some VCGs are specialized to inhabit the corn niche. The four most abundant VCGs (VCGs 2, 5, 8, and 9) in the soil were isolated $29,10,14$, and 14 times, respectively, and not as readily isolated from the corn kernels $(0,1,0$, and 2 isolates). Previous studies characterize A. flavus isolates in the soil and indicate that these isolates are potential threats to contaminate the crops with aflatoxin $(32,37)$. Our results suggest that the most abundant VCGs confined to soil (VCGs 2, 5, 8, 9, and undetermined VCGs) may not infect corn and, therefore, do not threaten to contaminate the corn with aflatoxin. Here, the abundance of a soil VCG was not predictive of the A. flavus strains that would be a threat to the crop. The majority of corn kernel isolates consisted of two VCGs (81\% VCG1 and 9\% VCG4) which were found at only 1.7 and $2.1 \%$, respectively, in the soil. These two VCGs were isolated from corn kernels in all 11 fields whereas they were only isolated from soil samples in 3 fields: 1 field with VCG1, 1 with both VCG1 and -4, and 1 with VCG4. The fact that these two VCGs were so abundant in corn compared with soil may indicate that they were better adapted to live in the corn niche than other VCGs found in the soil and may suggest that the source of inoculum for corn is outside the boundaries of the field.

Previous work has demonstrated that VCGs consist of isolates with the same sclerotia and aflatoxin production phenotypic characteristics as well as the same mating type $(6,18,20,22$, $23,30,31,47)$. Our results confirmed that most isolates within a VCG also had the same mating type locus. However, 1 isolate in VCG1 had a different mating type than the other 70 isolates. This anomalous isolate could be the result of the reassortment of genes between isolates from two different VCGs. The occurrence of mating is supported by the fact that the SSR haplotype is very different than any of the other SSR haplotypes within this VCG. This may be the first evidence of the sexual cycle of $A$. flavus occurring in nature. Isolates within the same VCGs in this study produced similar quantities of $\mathrm{AFB}_{1}$. However, VCGs 1, 4, 7, 8, 9, 10,13 , and 14 were composed of isolates which produced different sclerotial size classes. In VCGs 10 and 13, 5 of 12 and 2 of 3 isolates, respectively, produced an equal proportion of small and large sclerotia. This indicates that classifying isolates as

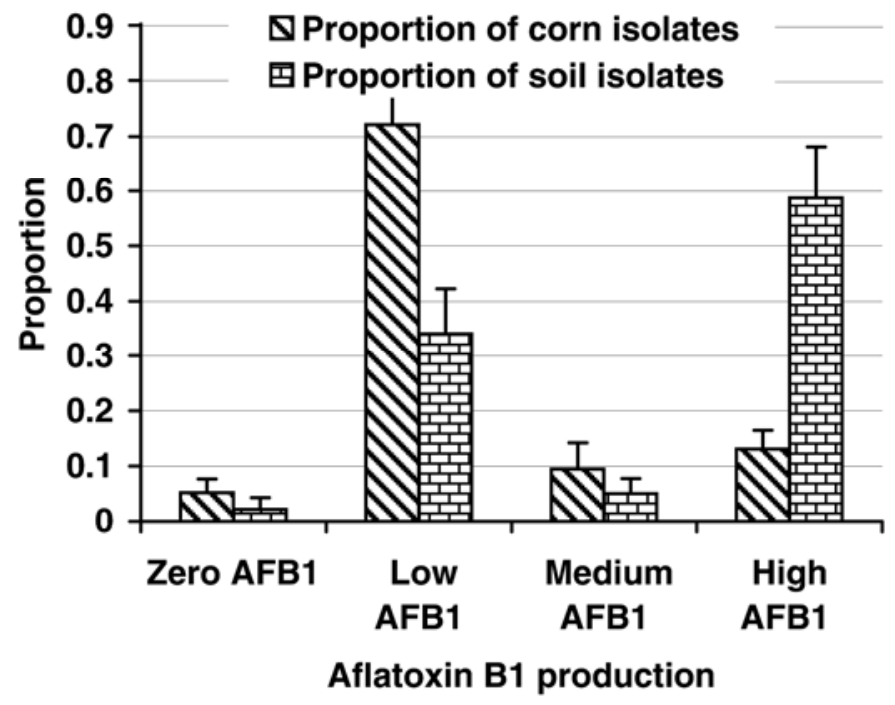

Fig. 2. Difference in the aflatoxigenicity of corn and soil isolates of Aspergillus flavus. Bars represent the mean proportion of soil or corn A. flavus isolates with aflatoxin $\mathrm{B}_{1}\left(\mathrm{AFB}_{1}\right)$ production category $\mathrm{X}$ in each sample. Error bars are upper $95 \%$ confidence limit. Low $\mathrm{AFB}_{1}=\mathrm{AFB}_{1}>0$ and $\leq 20 \mathrm{ppb}$ $\mathrm{AFB}_{1}$, Medium $=\mathrm{AFB}_{1}>20 \mathrm{ppb}$ and $\leq 300 \mathrm{ppb}$, and High $=\mathrm{AFB}_{1}>300 \mathrm{ppb}$. 
producing small or large sclerotia does not account for all the phenotypic variability within strains of A. flavus.

Sclerotia and toxin production are not ideal characteristics to show the differences between populations. Geiser showed that large and small sclerotia are not phylogenetically related characteristics by comparing three genes of 28 different $A$. flavus isolates (14). Therefore, small or large sclerotial size does not show if isolates within a population are related, making it hard to compare populations of $A$. flavus using this criterion. The sclerotial production and size may be affected by growing conditions. It has been found that some isolates of A. flavus will produce sclerotia more readily in the dark; accordingly, our sclerotial results are for growth on PDA in ambient light at $30^{\circ} \mathrm{C}(8,49)$. Regardless, only $5 \%$ of corn isolates produced sclerotia, whereas $97 \%$ of soil isolates produced sclerotia under these conditions. Sclerotia are important for survival of A. flavus in the harsh soil environment. The fact that the majority of corn isolates failed to produce sclerotia indicates that these isolates may not be as specialized to inhabit soil but, indeed, have become specialized to inhabit the corn niche. Also, the genes for aflatoxin production are located in the subtelomeric region of chromosome III, leading to potentially high mutation rates and large variability in aflatoxin synthesis $(8,21,51)$. Aflatoxin synthesis has been shown to be quickly lost after serial transfers on PDA; therefore, the aflatoxin quantification of isolates may not represent what the isolate produced in the field. Additionally, closely related isolates may have very different aflatoxin synthesis abilities (21). It is noteworthy that the majority of corn isolates produce only small quantities of $\mathrm{AFB}_{1}$, indicating that the production of aflatoxin is not essential for infection of corn, whereas the majority of soil isolates produced large amounts of aflatoxin, indicating that aflatoxin production might be important for survival in the soil niche. AIC values are used to compare the goodness of fit of general linear models; the smallest AIC is best. Accordingly, the general linear model with sclerotia size classes had the lowest AIC value of 1,454 which meant that, statistically speaking, the difference in sclerotia sizes best explained the differences between soil and corn kernel populations, not toxin production or VCG. In spite of this, a closer examination of these differences reveals that the difference in sclerotia and aflatoxin production between the two populations was a result of the absence of sclerotia in VCG1 and VCG4, and 90\% of VCG1 isolates produced low levels of aflatoxin in the corn (Table 2). VCG1 accounted for $81 \%$ and VCG4 for $9 \%$ of corn nit mutants and both accounted for only $4 \%$ of the soil nit mutants. In summary, the difference in VCGs better differentiated the soil and corn kernel isolates and, thus, the corn and soil A. flavus populations.
Eight SSR loci and mating type loci were also used to compare the soil and corn kernel populations (Table 3) (26). Similar to a RFLP study conducted in a corn field in Illinois, the SSR loci haplotypes were very different between the soil and corn kernel populations (50). Only one haplotype was shared between the soil and corn kernel isolates in this study. This was a haplotype for VCG1 and was represented by 1 soil isolate and 12 corn kernel isolates. In the Illinois study (50), no genotypes predominated in the corn kernel or soil isolates but, among the Louisiana isolates, there were only 26 different haplotypes out of 99 corn kernel isolates and 78 different haplotypes out of 91 soil isolates, and the most common haplotype was found 35 times in the corn. However, much like in the Illinois corn field, the corn isolate haplotypic diversity was smaller than soil isolates in every field (Table 3) (50). The fact that only one haplotype was shared between the corn and soil isolates and the soil isolates were more diverse supports the VCG results that isolates in the corn have become specialized to infect the corn. The distribution of Mat1-1 and Mat1-2 loci was different between the soil and corn kernel

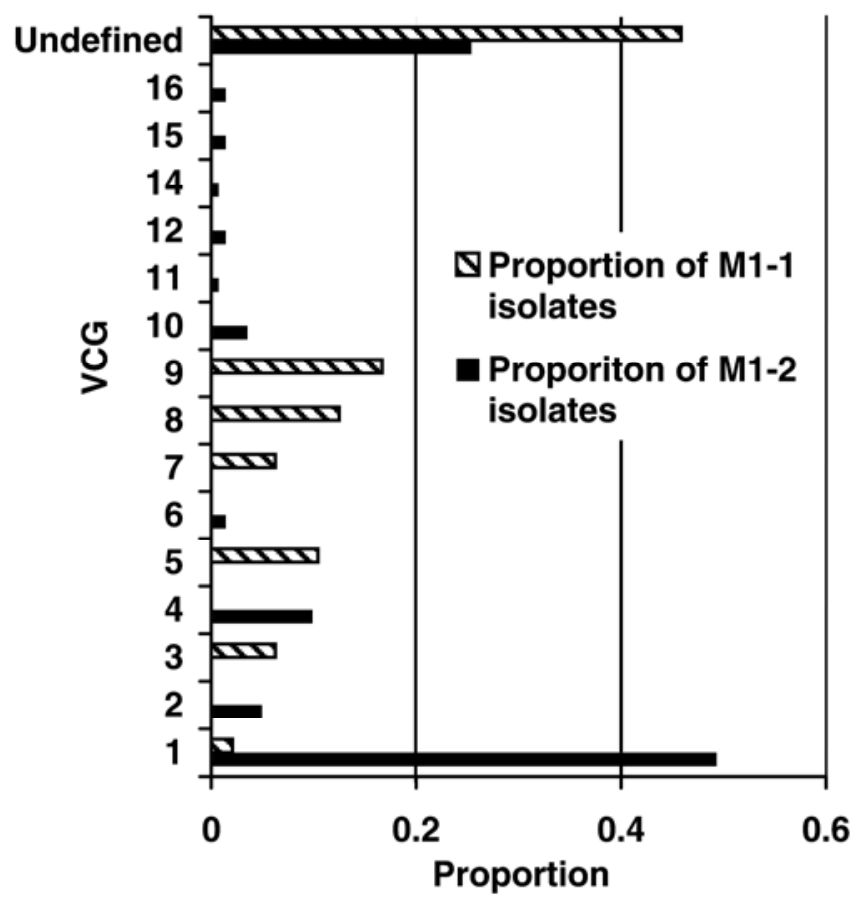

Fig. 3. Mat1-1 and Mat1-2 mating type locus distribution among Aspergillus flavus vegetative compatibility groups (VCGs). Bars represent the proportion of Mat1-1 or Mat1-2 A. flavus isolates in each VCG.

TABLE 3. Corn and soil Aspergillus flavus simple-sequence repeat (SSR) haplotype diversity (HD)

\begin{tabular}{|c|c|c|c|c|c|c|c|c|}
\hline \multirow[b]{3}{*}{ Field } & \multicolumn{4}{|c|}{ Soil } & \multicolumn{4}{|c|}{ Corn } \\
\hline & \multicolumn{3}{|c|}{ Number of } & \multirow[b]{2}{*}{$\mathrm{HD}^{\mathrm{z}}$} & \multicolumn{3}{|c|}{ Number of } & \multirow[b]{2}{*}{$\mathrm{HD}^{2}$} \\
\hline & Isolates & Haplotypes & Shared $^{\mathrm{y}}$ & & Isolates & Haplotypes & Shared $^{\mathrm{y}}$ & \\
\hline Batchelor & 9 & 7 & $1 \mathrm{P}$ & 0.9 & 9 & 3 & $2 \mathrm{C}$ & 0.7 \\
\hline Beggs & 2 & 2 & 0 & 1 & 9 & 3 & $1 \mathrm{~B}, 4 \mathrm{C}, 4 \mathrm{E}$ & 0.7 \\
\hline Belcher & 9 & 6 & 0 & 0.9 & 9 & 3 & $7 \mathrm{C}, 1 \mathrm{E}$ & 0.4 \\
\hline Chenyville & 9 & 8 & $1 \mathrm{P}$ & 1 & 9 & 2 & $4 \mathrm{C}, 5 \mathrm{G}$ & 0.6 \\
\hline Crowville & 9 & 8 & $2 \mathrm{~K}, 1 \mathrm{R}$ & 1 & 9 & 5 & $3 \mathrm{C}, 3 \mathrm{D}, 1 \mathrm{H}$ & 0.8 \\
\hline Frogmore & 8 & 7 & 0 & 0.9 & 9 & 3 & $7 \mathrm{~A}, 1 \mathrm{C}$ & 0.4 \\
\hline Macon Ridge Research Station & 9 & 8 & $2 \mathrm{H}$ & 1 & 9 & 4 & $4 \mathrm{D}, 3 \mathrm{H}$ & 0.8 \\
\hline St. Joseph & 9 & 8 & 0 & 1 & 9 & 3 & $4 \mathrm{~A}, 4 \mathrm{C}$ & 0.7 \\
\hline Northeast Research Station & 9 & 9 & $1 \mathrm{R}$ & 1 & 9 & 8 & $1 \mathrm{C}$ & 1 \\
\hline Torbert & 9 & 9 & 0 & 1 & 9 & 4 & $1 \mathrm{~A}, 6 \mathrm{~B}, 1 \mathrm{C}, 1 \mathrm{E}$ & 0.6 \\
\hline Washington & 9 & 9 & $1 \mathrm{~A}$ & 1 & 9 & 4 & $6 \mathrm{C}$ & 0.6 \\
\hline
\end{tabular}

y Haplotypes shared between fields. Letters represent unique SSR haplotypes (corresponding to letters in Table 2).

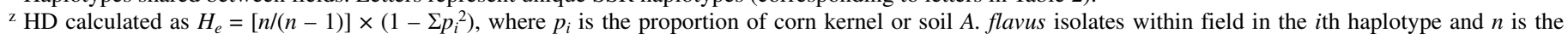
number of isolates from either the soil or corn kernels within a field. 
isolates of A. flavus. The two Mat loci were evenly distributed among soil isolates whereas $96 \%$ of the corn isolates were Mat12. The even distribution of Mat loci is consistent with the soil being the site of sexual reproduction (36). The predominance of Mat1-2 among the corn isolates may suggest that it confers a selective advantage to colonize corn. Much like the aflatoxin and sclerotia production, the difference in mating types was directly related to the predominance of VCG1, -4 , and -10 in the corn kernel population. All the corn kernel isolates in VCG1, -4 , and -10 were Mat1-2 mating type and these accounted for $87 \%$ of the corn kernel subsample isolates and only $3 \%$ of the soil subsample isolates.

The eight SSR loci were poor predictors of VCGs (43) in contrast to the results of Grubisha and Cotty (18). SSR loci, even if good predictors of VCGs, are not good genetic markers due to their high mutation rates (4). The mutation rates are high in SSR loci because of DNA polymerase slippage, leading to either the addition of repeats or the truncation of multiple repeats during DNA replication in mitosis. Currently there are no good population genetic models that account for the strange mutation rates of SSRs (4). This makes it hard to understand gene flow within a population and to be able to investigate population differentiation and migration and genetic drift of alleles (4). Stepwise mutation rates of single nucleotide differences are much better understood and have been incorporated into population genetics models; therefore, better genetic markers would consist of genes with single nucleotide differences (4).

More work needs to be done to understand why certain VCGs are more specialized to infect corn. The pathogenicity factors associated with certain VCGs could play a role in the differences in ability to colonize the plant. Oxylipin-generating dioxygenase mutants have been shown to affect the pathogenicity of $A$. flavus (24). Perhaps sequencing oxylipin-generating dioxygenases, other pathogenicity genes, or het genes would differentiate the isolates widely found in the corn and ones found in the soil $(9,12,24,51)$.

The fact that some isolates of $A$. flavus have a greater propensity to infect corn has several implications for aflatoxin contamination management. Currently, there are two avenues being explored to alleviate aflatoxin contamination: first is the use of a nontoxigenic $A$. flavus biocontrol and second is breeding resistant cultivars of corn $(9,18,25,31,51)$. In order to develop a successful biocontrol, the nontoxigenic biological control needs to be highly specific to infect corn in order to stack the deck in favor of biological control. Also, when screening for resistance to $A$. flavus, isolates should be chosen based on their demonstrated ability to infect corn under natural growing conditions. Our results indicate that there are differences between strains of $A$. flavus in their abilities to infect corn under natural growing conditions, and it should be assumed that there are genetic differences among strains and that these genetic differences affect pathogenicity.

\section{ACKNOWLEDGMENTS}

We thank the Louisiana Soybean and Grain Research and Promotion Board for financial support; growers J. Hunter, L. LaFleur, D. Marshall, R. Schexnayder, Jr., and D. VandeVen, who allowed access to their land and corn fields; F. Deville of Monsanto for collecting corn and soil samples; and C. DeRobertis for assistance in the field and lab. Dedicated to the memory of Robert P. Scheffer.

\section{LITERATURE CITED}

1. Abbas, H. K., Weaver, M. A., Zablotowicz, R. M., Horn, B. W., and Shier, W. T. 2005. Relationships between aflatoxin production and sclerotia formation among isolates of Aspergillus section Flavi from the Mississippi Delta. Eur. J. Plant Pathol. 112:283-287.

2. Aime, M. C., and Phillips-Mora, W. 2005. The causal agents of witches' broom and frosty pod rot of cacao (chocolate, Theobroma cacao) form a new lineage of Marasmiaceae. Mycologia 97:1012-1022.

3. Atehnkeng, J., Ojiambo, P. S., Donner, M., Ikotun, T., Sikora, R. A., Cotty, P. J., and Bandyopadhyay, R. 2008. Distribution and toxigenicity of Aspergillus species isolated from maize kernels from three agroecological zones in Nigeria. Int. J. Food Microbiol. 122:74-84.

4. Balloux, F., and Lugon-Moulin N. 2002. The estimation of population differentiation with microsatellite markers. Mol. Ecol. 11:155-165.

5. Bayman P., and Cotty, P. J. 1991. Improved media for selecting nitratenonutilization mutants in Aspergillus flavus. Mycologia 83:311-316.

6. Bayman, P., and Cotty, P. J. 1991. Vegetative compatibility and genetic diversity in Aspergillus flavus population of a single field. Can. J. Bot. 69:1707-1711.

7. Bell, D. K., and Crawford, J. L. 1967. A botran-amended medium for isolation Aspergillus flavus from peanuts and soil. Phytopathology 57:939-941.

8. Bennett, J. W., and Fernholz, F. A. 1978. Effect of light on aflatoxins, anthraquinones and, sclerotia in Aspergillus flavus and A. parasiticus. Mycologia 70:104-116.

9. Bhatnagar, D., Cary, J. W., Ehrlich, K., Yu, J., and Cleveland, T. E. 2006. Understanding the genetics of regulation of aflatoxin production and Aspergillus flavus development. Mycopathologia 162:155-166.

10. Bothast, R. J., and Fennell, D. I. 1974. A medium for rapid identification and enumeration of Aspergillus flavus and related organisms. Mycologia 66:365-369.

11. Cotty, P. J., and Taylor, D. R. 2003. Influence of complementation medium composition on vegetative compatibility analyses of Aspergillus flavus. (Abstr.) Phytopathology 93:S18.

12. Fedorova, N. D., Harris, S., Chen, D., Denning, D. W., Yu, J., Cotty, P. J., and Nierman, W. C. 2009. Using aCGH to study intraspecific genetic variability in two pathogenic molds, Aspergillus fumigatus and Aspergillus flavus. Med. Mycol. 47:S1-S8.

13. Garrett, K. A., Madden, L. V., Hughes, G., and Pfender, W. F. 2004. New applications of statistical tools in plant pathology. Phytopathology 94:999-1003.

14. Geiser, D. M., Dorner, J. W., Horn, B. W., and Taylor, J. W. 2000. The phylogenetics of mycotoxin and sclerotium production in Aspergillus flavus and Aspergillus oryzae. Fungal. Genet. Biol. 31:169-179.

15. Geiser, D. M., Pitt, J. I., and Taylor, J. W. 1998. Cryptic speciation and recombination in the aflatoxin-producing fungus Aspergillus flavus. Proc. Natl. Acad. Sci. USA 95:388-393.

16. Giorni, P., Magan, N., Pietri, A., Bertuzzi, T., and Battilani, P. 2007. Studies on Aspergillus section Flavi isolated from maize in Northern Italy. Int. J. Food Microbiol. 113:330-338.

17. Grubisha, L. C., and Cotty, P. J. 2009. Twenty-four microsatellite markers for the aflatoxin producing fungus Aspergillus flavus. Mol. Ecol. Resour. 9:264-267.

18. Grubisha, L. C., and Cotty, P. J. 2010. Genetic isolation among sympatric vegetative compatibility groups of the aflatoxin-producing fungus Aspergillus flavus. Mol. Ecol. 19:269-280.

19. Holsinger, K. E., and Weir, B. S. 2009. Genetics in geographically structured populations: Defining, estimating and interpreting Fst. Nat. Rev. 10:639-650.

20. Horn, B. W. 2003. Ecology and population biology of aflatoxigenic fungi in soil. Toxin Rev. J. Toxicol. 22:351-379.

21. Horn, B. W., and Dorner, J. W. 2001. Effect of competition and adverse culture conditions on aflatoxin production by Aspergillus flavus through successive generation. Mycologia 94:741-751.

22. Horn, B. W., and Greene, R. L. 1995. Vegetative compatibility within populations of Aspergillus flavus, A. parasiticus, and A. tamarri from a peanut field. Mycologia 87:324-332.

23. Horn, B. W., Moore, G. G., and Carbone, I. 2009. Sexual reproduction in Aspergillus flavus. Mycologia 101:423-429.

24. Horowitz Brown, S., Scott, J. B., Bhaheetharan, J., Sharpee, W. C., Milde, L., Wilson, R. A., and Keller, N. P. 2009. Oxygenase coordination is required for morphological transition and the host-fungus interaction of Aspergillus flavus. Mol. Plant-Microbe Interact. 22:882-894.

25. Huang, C. 2007. Mechanism of intraspecific toxin inhibition in Aspergillus flavus. Master's thesis, Louisiana State University, Baton Rouge.

26. Huang, C., Sweany, R., DeRobertis, C., Jha, A., and Damann, K. 2006. SSR fingerprinting analysis of vegetative compatibility groups in Aspergillus flavus. In: Proc. 6th Annu. Fungal Genomics, 7th Annu. Multi-crop Fumonisin, and 17th Annu. Multi-crop Aflatoxin Elimination Workshops.

27. Joshua, H. 1993. Determination of aflatoxins by reversed-phase highperformance liquid chromatography with post-column in-line photochemical derivatization and fluorescence detection. J. Chromatogr. 654:247-254.

28. Klich M. 2002. Identification of Common Aspergillus Species. Centraalbureeau voor Schimmelculture, Utrech, The Netherlands. 
29. Marsh, S. F., and Payne, G. A. 1984. Preharvest infection of corn silks an kernels by Aspergillus flavus. Phytopathology 74:1284-1289.

30. McAlpin, C. E., and Wicklow, D. T. 2002. DNA fingerprinting analysis of vegetative compatibility groups in Aspergillus flavus from a peanut field in Georgia. Plant Dis. 86:254-258.

31. Mehl, H. L., and Cotty, P. J. 2010. Variation in competitive ability among isolates of Aspergillus flavus from different vegetative compatibility groups during infection. Phytopathology 100:150-159.

32. Orum, T. V., Bigelow, D. M., Nelson, M. R., Howell, D. R., and Cotty, P. J. 1997. Spatial and temporal patterns of Aspergillus flavus strain composition and propagule density in Yuma County, Arizona, soils. Plant Dis. 81:911-916.

33. Papa, K. E. 1986. Heterokaryon incompatibility in Aspergillus flavus. Mycologia 78:98-101.

34. Pildain, M. B., Frisvad, J. C., Vaamonde, G., Cabral, D., Varga, J., and Samson, R. A. 2008. Two novel aflatoxin-producing Aspergillus species from Argentinean peanuts. Int. J. Syst. Evol. Microbiol. 58:725-735.

35. Pitt, J. I., Hocking, A. D., and Glenn, D. R. 1983. An improved medium for the detection of Aspergillus flavus and A. parasiticus. J. Appl. Bacteriol. 54:109-114.

36. Ramirez-Prado, J. H., Moore, G. G., Horn, B. W., and Carbone, I. 2008. Characterization and population analysis of the mating-type genes in Aspergillus flavus and Aspergillus parasiticus. Fungal. Genet. Biol. 49:1292-1299.

37. Razzaghi-Abyaneh, M., Shams-Ghahfarokhi, M., Allameh, A., KazeroonShiri, A. Ranjbar-Bahadori, S., Mirzahoseini, H., and Rezaee, B. 2006. A survey on distribution of Aspergillus section Flavi in corn field soils in Iran: Population patterns based on aflatoxin, cyclopiazonic acid and sclerotia production. Mycopathologia 161:183-192.

38. Rodrigues, P., Soares, C., Kozakiewicz, Z., Paterson, R. R. M., Lia, N., and Venancio, A. 2007. Identification and characterization of Aspergillus flavus and aflatoxins. Pages 527-534 in: Communicating Current Research and Educational Topics and Trends in Applied Microbiology. A. Mendez-Vilas, ed. Formatex, Badajoz, Spain.

39. Shotwell, O. L., Hesseltine, R. D., Stubblefield, R. D., and Sorenson, W.
G. 1966. Production of aflatoxin on rice. Appl. Microbiol. 14:425-428

40. Sobolev, V. S., and Dorner, J. W. 2002. Cleanup procedure for determination of aflatoxins in major agricultural commodities by liquid chromatography. J. AOAC Int. 85:642-645.

41. Slatkin, M. 1995. A measure of population subdivision based on microsatellite allele frequencies. Genetics 139:457-462.

42. St. Leger, R. J., Screen, S. E., and Shums-Pirzadeh, B. 2000. Lack of host specialization in Aspergillus flavus. Appl. Environ. Microbiol. 66:320-324.

43. Sweany, R. R. 2010. A comparison of soil and corn kernel Aspergillus flavus populations: Evidence for niche specialization. Master's thesis, Louisiana State University, Baton Rouge.

44. Vaamonde, G., Patriarca, A., Fernandez Pinto, V., Comerio, R., and Degrossi, C. 2003 Variability of aflatoxin and cyclopiazonic acid production by Aspergillus section Flavi from different substrates in Argentina. Int. J. Food Microbiol. 88:79-84.

45. Varga, J., Frisvad, J. C., and Samson, R. A. 2009. A reappraisal of fungi producing aflatoxins. World Mycotoxin J. 2:263-277.

46. Vendramin, G. G., Anzidei, M., Madaghiele, A., and Bucci, G. 1998. Distribution of genetic diversity in Pinus pinaster Ait. as revealed by chloroplast microsatellites. Theor. Appl. Genet. 97:456-463.

47. Wicklow, D. T. 1991. Epidemiology of Aspergillus flavus in corn. Pages 315-328 in: Aflatoxin in Corn: New Perspectives. O. L. Shotwell and C. R. Hurburgh, Jr., eds. Iowa Agric. Home Econ. Exp. Stn. Res. Bull. 599, Ames.

48. Wicklow, D. T., Bobell, J. R., and Palmquist, D. E. 2003. Effect of intraspecific competition by Aspergillus flavus on aflatoxin formation in suspended disk culture. Mycol. Res. 107:617-623.

49. Wicklow, D. T., Horn, B. W., and Cole, R. J. 1982. Sclerotium production by Aspergillus flavus on corn kernels. Mycologia 74:398-403.

50. Wicklow, D. T., McAlpin, C. E., and Platis, C. E. 1998. Characterization of the Aspergillus flavus population within an Illinois maize field. Mycol. Res. 102:263-268.

51. Yu, J., Cleveland, T. E., Nierman, W. C., and Bennett, J. W. 2005. Aspergillus flavus genomics: Gateway to human and animal health, food safety, and crop resistance to diseases. Rev. Iberoam. Micol. 22:194-202. 